\title{
A aplicabilidade da identificação documental em arquivos pessoais: uma reflexão
}

La aplicabilidad de la identificación documental en archivos personales: una reflexión

The applicability of archive identification in personal archives: a reflection

Sonia TROITIÑO, Gabrieli Aparecida da FONSECA

Departamento de Ciência da Informação, Faculdade de Filosofia e Ciências (UNESP-Marília), Av. Hygino Muzzi Filho, 737 - Marília - SP - BRASIL. smtr@marilia.unesp.br. gabrieli.arq@gmail.com

\section{Resumen}

Se aborda la aplicabilidad de la identificación documental en archivos personales. Así, nos proponemos evidenciar el papel del procedimiento denominado identificación documental en la organización de archivos personales. De esa manera, exploramos la hipotesis de que la identificación documental puede colaborar en mucho para garantizar que el tratamiento y custodia de los documentos de archivos personales sean apropiados, pues permite valerse de un profundo estudio de la génesis documental, en busca de la procedencia, para recuperar y evidenciar elementos inerentes al archivo en sus diferentes niveles.

Palabras clave: Identificación documental. Organización de archivos. Archivos personales.

\section{Introdução}

Surgida nos anos 1980 , os estudos de Identificação Documental se voltaram, em larga medida, para o problema da massa documental acumulada e para implantação de programas de gestão documental, de modo a otimizar o sistema de produção, controle e difusão de documentos dentro da organização administrativa da qual emanam. Contudo, no que se refere aos estudos sobre identificação documental em arquivos pessoais, raros são os trabalhos que envergaram por tal viés. Dessa ausência, inevitavelmente questões relativas a busca da proveniência dos documentos de origem particular, especialmente quando amparados pela identificação documental, surgiram.

Diante dessa motivação, o presente artigo busca realizar algumas considerações sobre a aplicabilidade da Identificação Documental em Arquivos Pessoais. O texto ora apresentado é fruto de uma reflexão conjunta a partir de dois projetos de pesquisa distintos, mas que se complementam.

O projeto "Relação entre custódia e tratamento documental: investigação sobre procedimentos arquivísticos de incorporação de acervos", sob coordenação de Sonia Troitiño (UNESP-

\begin{abstract}
The applicability of archival identification to personal archives is explored. The goal is to evidence the role of archival identification in the organization method of personal papers. In this sense, the hypothesis is explored that archival identification contributes largely to ensure to the appropriate treatment and custody of personal records, because it involves a deep study of the genesis of the archive, with the purpose to investigate its provenance, retrieve and show its inherent elements in their various levels
\end{abstract}

Keywords: Archival identification. Archival organization. Personal papers.

Marília/CNPq, Brasil), busca refletir sobre a adoção de protocolos de trabalho em arquivos, embasados na teoria arquivística, de modo a racionalizar os procedimentos adotados para a incorporação e disponibilização de acervos à sociedade, especialmente no que tange temas como identificação e avaliação documental com ênfase em documentos recebidos extrasistema de gestão documental, como os de origem pessoal.

A esta reflexão, se uniu à estudada pelo projeto "Identificação Documental: análise críticocomparativa de diferentes concepções", de responsabilidade de Gabrieli Aparecida da Fonseca (UNESP-Marília, Brasil) que atualmente encontra-se em desenvolvimento, no que diz respeito ao emprego da Identificação Documental, enquanto metodologia arquivística, para a precisa contextualização da informação relativa a acervos pessoais. Constatou-se na literatura da área a presença de diferentes entendimentos sobre o conceito de Identificação Documental, conforme a corrente arquivística da qual derivam. Desse modo, a pesquisa procurou perceber como se dão os desdobramentos práticos, no momento da organização da informação, quando realizados a partir de distintas matrizes teóricas. 
Ambos trabalhos de investigação confluem ao refletirem sobre a aplicabilidade da Identificação Documental em arquivos não institucionais, no que diz respeito aos desafios e benefícios por ela trazidos.

Para melhor debater este tema, tomaremos um estudo de caso concreto, a partir do qual será realizada a análise dos procedimentos de tratamento documental, fundamentados na Identificação Documental, do Fundo Fernando Henrique Cardoso, de propriedade da Fundação Instituto Fernando Henrique Cardoso (FiFHC, Brasil). Desse modo, procuramos neste espaço aliar reflexão teórica a da praxe arquivística.

\section{Identificação documental}

Diante do aumento da produção documental em nossa sociedade, o emprego de métodos eficazes na organização documental se faz imprescindível. Assim, a Identificação Documental surge como alternativa para melhor contextualizar e tratar massas documentais acumuladas. De acordo com Ana Célia Rodrigues ( 2011, p. 110):

O termo identificação surgiu no âmbito da arquivística, nos anos 80 , para designar as pesquisas desenvolvidas por grupos de arquivistas preocupados com a formulação de metodologias ou para solucionar o problema da acumulação irregular de documentos, que se contrapunha ao emergente desafio de implantar programas de gestão documental em países ibero-americanos.

A Identificação Documental, enquanto método de trabalho tem se posto como solução para organizar arquivos, respeitando os princípios de sua ciência. Essa utilidade decorre do fato da Identificação Documental se pautar em um estudo profundo da gênese documental, o qual analisa órgão produtor, tipologia e conteúdo (Rodrigues, 2011).

Dessa forma, cabe ao arquivista analisar e aplicar o método da maneira mais adequada, pois, como ressalta Concepción Mendo Carmona (2004, p. 38), organizar a documentação é tarefa que cabe ao arquivista e o resultado dessa organização se traduz no reconhecimento de características da documentação e seu meio:

[...] hemos de decir que la organización no la crea el archivero, le viene impuesta por la propia documentación; a él sólo le toca reconstruirla, rehacerla. En definitiva, viene impuesta por la persona o administración que la produjo. El archivero tiene que identificarla y, si la documentación se encuentra fragmentada o desorganizada, entonces sólo le resta reorganizarla, respetando los principios rectores de la archivística.
Nesse sentido, é de suma importância que os estudos teóricos se voltem para o tratamento documental, de modo a melhor amparar o processo de organização arquivística.

Entretanto, o que se nota é que o atual estado da arte dos estudos sobre Identificação Documental ainda é insuficiente para subsidiar sua prática adequada. Considerando tratar-se de um método recente, segue carecendo de investigações que embase seu escopo teórico.

A esse propósito, Maria Luisa Conde Villaverde (2006, p. 33) destaca a importância da sincronia entre prática e teoria para a realização de um bom trabalho:

[...] la teoría necesita de la práctica para ser real y la práctica necesita de la teoría para continuar siendo innovadora. La práctica, por lo tanto, consistiría en el cuestionamiento sistemático de la teoría, y, a su vez, en el cuestionamiento sistemático de la práctica estaría la esencia de la teoría.

A relação de sincronia entre teoria e prática é de fato muito importante, pois são duas dimensões deve andar emparelhadas. Como exemplo dessa relação, podemos fazer menção às fichas de identificação de documentos, nas quais a padronização, tanto da definição dos campos descritivos, quanto das informações coletadas, revela-se essencial para o trabalho em arquivo.

A possibilidade de construção de modelos universais para a representação de elementos documentais (contexto/forma/conteúdo), desponta como um "oasis" metodológico, no qual o denominador comum arquivístico assume papel predominante ao guiar o processo de descrição arquivística. Os parâmetros internacionais ISAAD (g), ISAAR cpf, ISDF, ISDIAH; e as nacionais ou regionais - NOBRADE (Brasil), NEDA (Espanha), NOGADA (Galícia, Espanha) ou NODAC (Catalunha, Espanha), entre outras sem falar nos diversos outros standards, tal qual as inúmeras ISO, têm se posto como importantes instrumentos das práxis arquivísticas.

Contudo, importa antes entender os valores de referência que determinam os caminhos a serem seguidos durante os processos de organização de fundos documentais. Assumir e incorporar a Identificação Documental nesses processos, significar transpor a barreira do visível. Por amparar-se em um estudo profundo da gênese documental, a Identificação Documental ultrapassa a simples informação registrada e volta-se para a compreensão do contexto de produção documental, levando em consideração todos os seus determinantes.

No entanto, o emprego da identificação documental vai mais além do ato de representar, por 
meio da descrição. Ela antes se faz notar no processo classificatório e na construção de seus instrumentos-guia (plano de classificação e tabela de temporalidade). Desse modo, asume importancia basilar na gestão de documentos (Mendo Carmona, 2004, p.42):

La identificac(2006, p. 33).ión es la mejor herramienta para aplicar el principio básico de la archivística: el de respeto a la procedencia y a la estructura interna del fondo. Consiste en la investigación de las características de los dos elementos implicados en la génesis del fondo: el sujeto productor y el objeto producido. Se entiende por sujeto productor la persona física, familia $u$ organismo que ha producido y/o acumulado el fondo. Se entiende por objeto producido la totalidad del fondo y cada una de las agrupaciones documentales que lo conforman.

Desvendar as características dos documentos através dos aspectos que a Identificação Documental evidencia, nem sempre é tarefa simples, considerando a natureza do arquivo.

Neste artigo, vamos nos ater aos arquivos de indivíduos. Contudo, sempre é válido lembrar que mais do que o caráter público versus privado, a contraposição entre institucional e pessoal é reveladora da origem e uso dos documentos, nas quais as relações orgânicas revelam-se de forma diferenciada.

Nessa perspectiva, a arquivística volta-se, em larga medida, para a explicitação sobre a origem do documento e os agrupamentos decorrentes de sua classificação. Para Mendo Carmona (2004, p.42-43),

[...] La primera fase del análisis se centra en la identificación del organismo productor del fondo documental. [...] El segundo paso o fase de la identificación se centra en el análisis de cada una de las series documentales generadas.

Enfim, a Identificação Documental desempenha papel importante para a organização arquivística, possibilitando um trabalho com mais eficiência, já que a partir dela é possível subsidiar as etapas posteriores a sua própria aplicação, como a classificação, avaliação, descrição, entre outras.

\section{A importância da identificação documental em arquivos pessoais}

Não raramente, arquivos pessoais representam um desafio a ser enfrentado, pois, ainda que aceitos como conceitualmente arquivos, os métodos de organização documental a eles destinados costumam apoiar-se em fundamentação teórica e estruturação da informação elaborada com base em arquivos institucionais - mesmo que possuam lógica própria na formação e con- figuração de seus acervos. Constatação já evidenciada por Rob Fischer ao afirmar que

Private archives are poor cousin to government archives in the family of archival theory. Archivists who work with private archives often lamente the absence of a professional literature on which to base their work and thought about the archival endeavour. (Fischer, 2009, p. 2)

Além dessas barreiras para o reconhecimento, há também a questão sobre o entendimento do que é um arquivo pessoal ser muito amplo. Normalmente, o arquivo pessoal possui diversas facetas e dá abertura para interpretações díspares, ficando seu titular, muitas vezes, no limiar entre o guardador/acumulador de documentos de interesse particular e o agente proativo na reunião e preservação de registros documentais sobre suas atividades pessoais.

O Centro de Pesquisa e Documentação de História Contemporânea - Fundação Getúlio Vargas CPDOC - FGV (2012), no Brasil, é um dos principais centros de documentação especializado em organização de arquivos pessoais, sendo considerado referência no tratamento documental de fundos com tal perfil, cujos critérios e metodologia desenvolvida influência os trabalhos técnicos da área, desde os anos 19700 até atualidade. Segundo o CPDOC-FGV (2015),

Arquivos Pessoais, portanto, são conjuntos documentais, de origem privada, acumulados por pessoas físicas e que se relacionam de alguma forma às atividades desenvolvidas e aos interesses cultivados por essas pessoas, ao longo de suas de vidas. $[\ldots]$

Arquivos pessoais constituem valiosas fontes de pesquisa, seja pela especificidade dos tipos documentais que os caracterizam, seja pela possibilidade que oferecem de complementar informações constantes em arquivos de natureza pública.

Essa compreensão passa pelo entendimento dos tipos documentais e das relações orgânicas que permeiam a documentação de ordem pessoal como premissas fundamentais para o seu reconhecimento enquanto arquivo.

A Identificação Documental também pode contribuir para esse reconhecimento em razão de possibilitar a análise tanto individual, quanto articulada das unidades documentais dentro de seu conjunto orgânico, revelando além das características particulares de cada registro, elementos do contexto de acumulação e guarda, bastante significativos para a compreensão da constituição do fundo.

Conforme Rodrigues (2008, p. 118-119), a identificação assume papel primordial no tratamento de documentos arquivísticos, contribuindo para 
a compreensão da natureza dos arquivos e suas peculiaridades.

A identificação é um tipo de identificação científica particular que constituiu uma ferramenta particular de trabalho para o arquivista. Uma metodologia de pesquisa que se desenvolve, nos parâmetros do rigor científico, como uma tarefa preliminar e necessária às funções da classificação, avaliação, descrição, planejamento da produção documental. [...] Neste sentido, é um trabalho de pesquisa e de crítica sobre a gênese documental.

Nessa leitura, a identificação é um meio de potencializar a contextualização informacional fornecida pelo o tratamento documental arquivístico, em todas suas etapas, mas especialmente nos momentos de avaliação, classificação e descrição de documentos.

No caso especifico de arquivos pessoais, a lacuna ocasionada pela ausência de estudos de produção documental pode vir a ser minimizado a partir do emprego da Identificação Documental. Assim, o tratamento arquivístico de fundos pessoais pode se beneficiar de seus conceitos e técnicas, inclusive ampliando os usos para esse tipo de arquivo - destacando entre eles, potencialmente, o subsídio à administração e memória coletiva.

No sentido de demonstrar a importância da Identificação Documental na organização da informação de cunho pessoal é interessante destacar a experiência realizada pela Fundação Instituto Fernando Henrique Cardoso- FiFHC.

A FiFHC, é um exemplo de instituição arquivística com acervo pessoal a incorporar os preceitos da Identificação Documental em sua política de organização documental, tendo desenvolvido um método experimental, baseando a classificação e descrição do acervo nos eventos que deram origem aos documentos, optando por confrontar conteúdo e contexto como forma de fornecer maior completude ao acesso à informação. Essa experiência encontra-se relatada no livro Tempo e Circunstância: a abordagem conceitual dos arquivos pessoais (2007), elaborado pelas consultoras e idealizadoras da proposta, Ana Maria de Almeida Camargo e Silvana Goulart, sobre os arquivos de Fernando Henrique Cardoso e de sua esposa Ruth Corrêa Leite Cardoso. O livro traz uma reflexão acerca dos aspectos conceituais e metodológicos em torno dos arquivos pessoais, juntamente com a exposição da metodologia e resultados do trabalho de organização realizado na FiFHC, especialmente no que se refere à Identificação Documental e construção de instrumentos de acesso à informação.
É preciso também considerar que os relatos sobre a aplicação dessa proposta dizem respeito a fundos bastante "completos", ou seja, arquivos que mantiveram seu conjunto documental preservado por não haverem sido realizados descartes ou havido perdas que pudessem ocasionar lacunas. Sem dúvida, esta é uma considerável vantagem para o sucesso dessa experimentação.

Até porque, ao se eleger a metodologia mais adequada para o tratamento documental de determinado acervo, é sempre necessário ter em conta o impacto ocasionado pela ausência de documentos, no que diz respeito ao grau de comprometimento ocasionado por lacunas em um fundo.

No caso do Fundo Fernando Henrique Cardoso (FHC), há documentos de todos os períodos de sua vida, até pelo fato do próprio titular ter tomado o cuidado em preservar e atribuir certa organização aos seus documentos, ao longo da vida.

Sendo ex-presidente da república, a documentação referente ao período de atividade presidencial se destaca por possuir um esquema de identificação prévio relacionado com sua produção - vestígios de um momento de vida onde a figura pública e a vida particular se misturaram de modo indissociável.

No caso específico do fundo $\mathrm{FHC}$, o esquema original de identificação documental foi conservado parcialmente, com algumas modificações para que pudesse abranger documentos de outros períodos de vida de seu titular. De acordo com Priscila Fraiz (1998, p.62):

É raro que um arquivo pessoal chegue a uma instituição de memória com algum arranjo ou ordenamento prévios, determinado pelo próprio titular, por colaboradores ou mesmo por familiares; mais incomum ainda é encontrar um tipo de material que reflita e revele alguma ordem original ou primitiva, que possa nos dizer do arquivo e sobre o arquivo.

A experiência de tratamento documental da FiFHC se destaca pela opção metodológica empregada nas etapas de identificação, descrição e construção do banco de dados, como importantes ferramentas junto à classificação. De tal modo que, a forma como a Identificação Documental subsidia a organização arquivística na $\mathrm{FiFHC}$ e o enfoque dado às funções, mostra como a organização em Arquivos Pessoais pode ser flexível sem se desvincular dos princípios arquivísticos. Segundo Camargo e Goulart (2007, p. 89):

[...] o processo de identificação leva em conta as especificidades dos documentos de biblioteca e as dos diferentes gêneros documentais encontrados 
no arquivo, a entrada de dados se dá a partir de formulários próprios.

Ou seja, a identificação documental é capaz de evidenciar elementos inerentes aos documentos, levando em consideração o gênero próprio de cada um deles. Afinal, uma de suas vantagens é possibilitar a análise das unidades documentais individualmente, o que pode ser positivo para que se consiga lidar com as características específicas dos arquivos pessoais.

$\mathrm{Na}$ prática, trata-se de um trabalho minucioso, cujos dados nele extraídos das unidades documentais são armazenados no banco de dados, onde há módulos de descrição diferentes, conforme o gênero documental. Assim os documentos são identificados e registrados um a um, facilitando a recuperação da informação. (Camargo e Goulart, 2007)

Esses módulos, expressos pelos formulários presentes no banco de dados, possuem uma base comum, de modo que as variações em seus campos são sutis e ocorrem sempre em função do gênero documental. Contudo, o que pese privilegiar a linguagem documental (gênero) como fator de representação da informação, esta proposta de organização arquivística segue preservando a função e atividade como parâmetros de contextualização dos arquivos pessoais (Camargo e Goulart, 2007, p. 60):

A organização lógica do acervo, na área de arquivo, é norteada pela funcionalidade, isto é, pela identificação do elo entre os documentos e as atividades que lhes deram origem, de modo a garantir que, individual ou coletivamente, os diferentes itens que o integram possam evocar ou representar, de modo inequívoco, as circunstâncias e o contexto que justificaram sua acumulação e guarda.

Mas a organização física dos documentos também é algo que deve ser lembrado, pois está relacionada com o funcionamento do acervo. Compreende-se então que o mais importante na organização, é que esta aborde o contexto de produção dos documentos, permitindo assim embasar sua guarda.

Entretanto, em Arquivos Pessoais isso pode ser mais complexo devido à grande variedade de gêneros, formatos e tipos documentais (Camargo e Goulart, 2007, p. 61):

É preciso lembrar que a capacidade de representar o contexto de produção é mais acentuada nos documentos escritos, cuja vocação probatória repousa, em grande parte, no uso de convenções dotadas de grande força ilocucionária, no recurso a fórmulas redutoras de ambiguidade e na explicitação das circunstâncias em que foram produzidos. Ao promover o entendimento literal de seu conteúdo por meio de espécies e tipos facilmente reco- nhecidos, até quando adota modalidades discursivas ou discricionárias, o documento textual (que é o documento de arquivo, por excelência) evoca, pela palavra, sua própria funcionalidade, o que não ocorre com sons, imagens e objetos. Eis por que a identificação das unidades de descrição leva em conta o gênero documental.

O que se constata, não só na experiência da FiFHC, mas na organização de arquivos pessoais de um modo geral, é que a Identificação Documental contribui de modo significativo para a contextualização funcional de acervos pessoais, em razão de proporcionar a análise das unidades documentais agrupadas ou isoladamente, o que pode ser positivo para que se consiga lidar com as características específicas de arquivos de indivíduos. Nesse sentido, a identificação se destaca como um importante meio de potencializar o tratamento documental arquivístico.

\section{Concepções e perspectivas}

Diante da forma variável como a Identificação Documental é conceituada pelas diferentes correntes da Arquivologia, há diversos problemas que cercam sua aplicação concreta e seu reconhecimento enquanto método de trabalho. Neste texto, especificamente, discutiremos as relações entre a corrente espanhola e a brasileira, apontando suas semelhanças e divergências. Captar a essência presente em cada tendência, talvez, seja um caminho para compreender os sentidos atribuídos à Identificação Documental, seus procedimentos e usos.

A corrente espanhola é precursora nos estudos de Identificação Documental e trouxe grandes contribuições para a temática. Segundo Pedro López Gómez (1998, p. 39):

Por medio del análisis documental, y en el proceso de identificación de las distintas series documentales, pasamos desde los orígenes legislativos, normas, procedimiento y trámite que ha originado cada serie en concreto, al conocimiento del órgano emisor/receptor y sus funciones y competencias, las actividades desarrolladas en el ejercicio de las mismas, y la plasmación documental que se manifestaron, en el tiempo y a lo largo del tiempo.

Ou seja, a partir de uma acurada análise documental, aliada à identificação de séries documentais, é possível reunir informações relativas à posição hierárquica do documento em relação aos seus níveis superiores orgânicos, conforme a proveniência. Da mesma forma, é capaz de contribuir para o entendimento da configuração física e intelectual assumida pelo documento no ato de seu registro. 
Nesse sentido, a Identificação Documental, revela-se um importante instrumento para 0 estudo de produção documental, com vistas à contextualização da informação.

Ainda sobre a proveniência, Antonia Heredia Herrera (2003, p. 7) ressalta que não apenas o estudo da instituição é importante para essa construção, mas também a identificação das séries documentais, completando a ideia anterior:

Las soluciones a posteriori, siempre a destiempo, suponen una reconstrucción -nunca invenciónque exige conocimiento de la institución, de sus competencias materializadas en funciones y actividades, de su estructura, de la identificación de las series que son testimonio y prueba de dichas funciones y actividades.

Quanto à aplicação do método e aos aspectos que o permeiam, como o estudo do contexto e dos documentos, Maria Luísa Conde Villaverde (2006, p. 35).afirma que:

En efecto, a partir de ese momento la investigación en los archivos se centrará en los diferentes aspectos de la reconstrucción del contexto de producción de los documentos (identificación del sujeto productor, de su dimensión orgánica y funcional, etc.), así como de su caracterización como testimonio único de los hechos documentados (necesidad de su conservación permanente o posibilidad de selección y eliminación transcurrido el plazo de vigencia de sus valores administrativos; períodos de permanencia en cada una de las etapas de su ciclo vital; confidencialidad de su contenido informativo, etc.).

Entende-se, então, que a reconstrução do contexto de produção, possível por meio da Identificação Documental, relaciona-se com os demais procedimentos arquivísticos.

No Brasil, a discussão se afasta um pouco dessa perspectiva, quando um grupo de pesquisadores passa a compreender que a Identificação, além de possuir relação com as funções arquivísticas, também se trata de uma função. Ana Célia Rodrigues (2008, p. 13), uma das precursoras dessa abordagem, esclarece que

No contexto da identificação, os estudos teóricos desenvolvidos indicam que se trata de uma função arquivística, ainda sem sistematização. Os procedimentos formulados para reconhecer os documentos de arquivos e seus vínculos de proveniência e organicidade, é uma pesquisa preliminar desenvolvida que gera informações registradas em instrumentos próprios e são a base das análises para a avaliação, classificação, descrição e produção de documentos de arquivos

A sistematização citada por Ana Célia Rodrigues é um ponto muito importante, pois a Identificação Documental ainda não possui uma sis- tematização de suas etapas, de modo a facilitar sua prática.

Já, Sonia Troitiño (2015. p. 159) ao debater os mecanismos empregados para a atribuição de nomes a documentos, elenca três processos distintos, relacionando-os com a identificação documental, em alguma de suas fases:

Nomear: ato de dar nome pautando-se em critérios previamente estabelecidos, podendo ser amparado na legislação, em manuais, em padrões formulares, na história ou em qualquer outra base de apoio.

Reconhecer: processo vinculado à identificação documental. Por si só, apenas é possível reconhecer um documento e, imediatamente, o nome que Ihe é conferido quando esse nome já está bem consolidado.

Denominar: implica em dar um nome designativo, envolvendo fixação e determinação. É uma espécie de chamamento, no sentido de confirmação da conexão estabelecida entre o objeto e a expressão que o designa.

Esclarecendo, que o processo acima, refere-se à designação de documentos e não dos tipos documentais em si. Entretanto, os estudos de identificação documental são mais amplos, por tratar não só do documento, mas das relações intrínsecas e extrínsecas a eles inerentes. Ainda assim, são estudos extremamente úteis por proporcionar fundamento não só a designação do documento, mas a sua compreensão.

O fato é que independentemente da corrente de estudos arquivísticos, nota-se certa generalidade na forma de tratamento documental em relação à origem dos registros. Segundo Ana Maria de Almeida Camargo (2015. p. 14),

A nomeação adequada dos documentos, para fins de organização e descrição dos arquivos, tem sido bastante negligenciada. Na medida em que a própria disciplina arquivística se fundamenta nas práticas administrativas dos organismos públicos, em que predominam as ações sequenciais e seu correlato documental - os processos -, observa-se entre nós um curioso fenômeno: muitos profissionais se eximem de identificá-los, na suposição de que, sendo todos da mesma espécie, basta reconhecêlos pela função que cumprem ou pelo assunto de que tratam.

No Brasil, o conceito de tipo documental consolidou-se com a união da espécie documental (concepção formular) à função atrelada ao ato em si - procedimento em larga medida influenciado pelos estudos da arquivista Heloísa Liberalli Bellotto. Efetivamente, significa que documentos oriundos de atos administrativos, em geral respaldados em regras do direito e em manuais de procedimentos, possuem fácil reconhecimento de sua estrutura formular documen- 
tal. Dessa forma, relatórios de atividade, solicitação de férias, processo de admissão de pessoal são facilmente reconhecidos e seus nomes quase auto-explicativos dos conteúdos que carregam.

Contudo, documentos de arquivos pessoais, especialmente os de fórum íntimo, carecem de rigor na constituição de sua estrutura formular Ainda que, como bem lembra Duranti (1996), seja possível perceber certo padrão.

Da mesma forma, a função atrelada ao documento, próprio motivo de sua criação, usualmente é plural. Essa questão fica muito clara quando lidamos com a tão conhecida correspondência. Nas cartas, exemplo tão típico de registro da vida privada, em um mesmo documento, é possível que funções como saudar, convidar, relatar ou prestar homenagem se encontrem no mesmo discurso, assim dificultando a titulação documento, pois existe uma pluralidade de funções confluentes. Porém, a questão pode sofrer outros complicadores.

Fora as formas de expressão tradicionais, a contemporaneidade traz em seu bojo novas formas de expressão escrita, fruto das transformações nos relacionamentos. Assim, não raramente hoje, formas de comunicação mantidas através de emails, bate-papos, troca de mensagens utilizando serviços como Whatssap, Line ou similares, no âmbito privado, assumiram foro privilegiado pelas facilidades de comunicação que proporcionam como popularidade, agilidade, gratuidade, entre outros atrativos.

$\mathrm{Na}$ FiFHC, nosso estudo de caso, a título de exemplificação, a experiência com essas novas formas de comunicação representou um desafio a ser enfrentado, especialmente na eleição do nome designativo do documento.

Dessa forma, amplamente norteados pelos estudos de Identificação Documental, o grupo de estudiosos optou por designar determinada espécie de documento como Conversação (Camargo, 2015). Nome sem dúvida polêmico, mas que inegavelmente reflete a ação em si (conversa registrada). Evidentemente que para que uma conversa seja registrada é necessário um veículo, neste exemplo, ela se deu através da troca de email. E porque não simplesmente a palavra email foi utilizada? Talvez porque o termo endereço eletrônico seja um "guardachuva" amplo demais, o qual esconderia especificidades das unidades documentais.

Todavia, estas novas expressões documentais ainda não foram bem estudadas e carecem de pesquisas para sua melhor compreensão posto que o padrão formular que apresentam, oscila entre os tradicionalmente conhecidos, influenciados pelo costume, e as adaptações condicionadas pela tecnologia disponível e pelas novas formas de relacionamento.

Diante dos desafios impostos pela realidade que se apresenta, no que diz respeito ao reconhecimento e padronização de registros documentais, a Identificação Documental pode indubitavelmente colaborar para a racionalização do sistema organização e disponibilização de documentos.

\section{Considerações finais}

A Identificação Documental é um tema de grande importância para a arquivística, uma vez que explora especificidades dos documentos tais como órgão produtor, tipo documental, natureza, entre outros elementos constituintes do registro. Em arquivos pessoais, a Identificação Documental se destaca por possibilitar uma organização que vai além dos aspectos físicos do documento, já que permite uma visão mais ampla, aprofundada pelos estudos sobre proveniência e organicidade.

Compreender a lógica de formação dos arquivos pessoais é de suma importância para a organização dos mesmos, pois é através desta que serão representados enquanto arquivos. Consequentemente, estudos em direção à gênese são essenciais, principalmente quando a documentação se encontra desordenada. A Identificação Documental, nesses casos, é crucial e capaz de direcionar os trabalhos de organização arquivística.

Diante das considerações aqui postas, buscamos debater o modo como a Identificação Documental pode contribuir para o conhecimento circunstanciado do contexto funcional. Assim, o estudo de caso sobre os procedimentos de organização da informação desenvolvidos na FiFHC veio complementar nossa pesquisa por permitir a análise do tratamento documental destinado ao seu acervo, em busca da fundamentação proporcionada pelas práxis em arquivos aliada às bases teóricas de nosso campo de estudo.

Ao refletir sobre o papel da Identificação Documental no processo de organização de arquivos, sejam de origem institucional ou pessoal, pudemos constatar seu valor em primeiro lugar por sua capacidade de evidenciar a natureza e origem dos documentos, conforme a proveniência; em segundo lugar por auxiliar na construção do plano de classificação ao esclarecer as relações orgânicas entre os diferentes níveis hierárquicos; e em terceiro por contribuir para o estabe- 
lecimento de séries documentais tipológicas, através do reconhecimento de espécies e funções presentes nos registros das ações humanas no âmbito da vida privada.

No caso dos arquivos privados, as especificidades que tornam a organização dos arquivos pessoais mais complexa não devem dificultar ou impedir que os mesmos sejam tratados tal como arquivos que são, em conformidade com os princípios da Arquivologia.

Enfim, visto que os arquivos pessoais possuem especificidades que muitas vezes requerem tratamento documental personalizado, a Identificação Documental é uma grande aliada para a organização desses acervos, uma vez que não apenas recupera meios para organizar adequadamente a documentação, mas também valoriza e respeita a individualidade de cada arquivo.

\section{Referências}

Brasil. Conselho Nacional de Arquivos (2006). NOBRADE: Norma Brasileira de Descrição Arquivística. RJ: Arquivo Nacional.

Camargo, Ana Maria de Almeida (1998). Contribuição para uma Abordagem Diplomática dos Arquivos Pessoais. /I Revista Estudos Históricos. 11:21, 169-174. http://bibliotecadigital.fgv.br/ojs/index.php/reh/article/vie wArticle/2065 (2013-12-01).

Camargo, Ana Maria de Almeida (2015). Sobre espécies e tipos documentais. // Camargo, Ana Maria de Almeida et ali. Dar nome aos documentos: da teoria à prática / apresentação de Danielle Ardaillon. São Paulo: Instituto Fernando Henrique Cardoso.

Camargo, Ana Maria de Almeida; Goulart, Silvana (2007). Tempo e circunstância: a abordagem contextual dos arquivos pessoais-procedimentos metodológicos adotados na organização dos documentos de Fernando Henrique Cardoso. São Paulo: Instituto Fernando Henrique Cardoso.

Conde Villaverde, Maria Luísa (2006). La investigación em los archivos. Evolución de su contexto y contenido. // Arbor. CLXXXII:717, 32-37. http://arbor.revistas.csic.es/ index.php/arbor/article/view/5/5 (2013-12-01).

Conselho Internacional De Arquivos (Brasil) (2004). ISAAR(CPF): norma internacional de registro de autoridade arquivística para entidades coletivas, pessoas e famílias. $2^{\mathrm{a}}$ ed., Rio de Janeiro: Arquivo Nacional.

Conselho Internacional De Arquivos (Brasil) (2000). ISAD(g): Norma Geral Internacional de Descrição Arquivística: $2^{a}$ ed. rev., adotada pelo Comitê de Normas de Descrição, Estocolmo, Suécia, 19-22 de setembro de 1999, versão final aprovada pela CIA. Rio de Janeiro: Arquivo Nacional.

Conselho Internacional De Arquivos (2007). ISDF: Norma Internacional para a Descrição de Funções. $1^{\text {a }}$ ed., Rio de Janeiro: Arquivo Nacional.
Conselho Internacional De Arquivos (2008). ISDIAH: Norma Internacional para a Descrição de Instituições com Acervo Arquivístico. $1^{\text {a }}$ ed., Rio de Janeiro: Arquivo Nacional.

CPDOC, FGV (2013). O que são arquivos pessoais. http://cpdoc.fgv/acervo/arquivos pessoais (2013-12-01).

Duranti, Luciana ()1996. Diplomática: usos nuevos para uma antigua ciência. Sevilha, Espanha: S\&S Ediciones.

Espanha (2011). Comisión de Normas Españolas de Descripción Archivística (CNEDA). Modelo conceptual de descripción archivística y requisitos de datos básicos de las descripciones de documentos de archivo, agentes y funciones. Sevilla: Secretaría de la Comisión de Normas Españolas de Descripción Archivística.

Fischer, Rob (2009). In Search of a Theory of Private Archives: The Foundational Writings of Jenkinson and Schellenberg Revisited. // Archivaria. 67, p.1-24. http://journals.sfu.ca/archivar/index.php/archivaria/article /view/13205/14479 (2013-12-01).

Fraiz, Priscila (1998). A Dimensão Autobiográfica dos Arquivos Pessoais: o Arquivo de Gustavo Capanema. // Revista Estudos Históricos. 11:21, 59-87. http://bibliote cadigital.fgv.br/ojs/index.php/reh/article/viewArticle/2060 (2013-12-01).

Fundação Instituto Fernando Henrique Cardoso (2013). http://www.ifhc.org.br/ (2013-12-01).

Grupo de Arquiveiros de Galicia (2010). Norma gallega de descripción archivística (NOGADA), febrero 2010. $2^{\mathrm{a}}$ versión. Santiago de Compostela: Dirección Xeral do Patrimonio Cultural.

Heredia Herrera, Antonia (2003). El principio de procedência y los otros princípios de la archivística. São Paulo : Associação de Arquivistas de São Paulo.

López Gómez, Pedro (1998). Los archiveros y sus investigaciones. // Métodos de Información. 5:22-23, 37-43. http://eprints.rclis.org/5068/1/1998-22-37.pdf (2013-1201).

Mendo Carmona, Concepción (2004). Consideraciones sobre el método en archivistica. // Documenta \& Instrumenta. Madrid, Universidad Complutense de Madrid. 1, 35-46. http://revistas.ucm.es/index.php/DOCU/article/vie w/DOCU0404110035A/19190 (2013-12-01).

Rodrigues, Ana Célia (2008). Diplomática contemporânea como fundamento metodológico da identificação de tipologia documental em arquivos. São Paulo. www.teses.usp.br/teses/.../TESE_ANA_CELIA RODRIG UES.pdf (2013-12-01).

Rodrigues, Ana Célia (2011). Identificação: uma nova função arquivística. // Revista EDICIC. 1:4, 109- 129. http://www.edicic.org/revista/index.php?journal=RevistaE DICIC\&page=article\&op=view\&path\%5B\%5D=79\&path $\% 5 B \% 5 D=p d f(2013-12-01)$.

Troitiño, Sonia (2015). Atribuir nomes a tipos, séries e unidades documentais: dialogando com Mariano Garcia Ruipérez. // CAMARGO, Ana Maria et ali. Dar nome aos documentos: da teoria à prática / apresentação de Danielle Ardaillon. São Paulo: Instituto Fernando Henrique Cardoso.

Enviado: 2015-05-07. Segunda versión: 2016-01-07-. Aceptado: 2016-05-12. 